\title{
Age differences in collaborative memory: The role of retrieval manipulations
}

\author{
Michelle L. Meade \\ Montana State University, Bozeman, Montana \\ AND \\ HENRY L. ROEDIGER III \\ Washington University, St. Louis, Missouri
}

\begin{abstract}
In two experiments, we examined age differences in collaborative inhibition (reduced recall in pairs of people, relative to pooled individuals) across repeated retrieval attempts. Younger and older adults studied categorized word lists and were then given two consecutive recall tests and a recognition test. On the first recall test, the subjects were given free-report cued recall or forced-report cued recall instructions (Experiment 1) or free recall instructions (Experiment 2) and recalled the lists either alone or in collaboration with another subject of the same age group. Free-report cued recall and free recall instructions warned the subjects not to guess, whereas forcedreport cued recall instructions required them to guess. Collaborative inhibition was obtained for both younger and older adults on initial tests of free-report cued recall, forced-report cued recall, and free recall, showing that the effect generalizes across several tests for both younger and older adults. Collaborative inhibition did not persist on subsequent individual recall or recognition tests for list items. Older adults consistently falsely recalled and recognized items more than did younger adults, as had been found in previous studies. In addition, prior collaboration may exaggerate older adults' tendency toward higher false alarms on a subsequent recognition test, but only after a free recall test. The results provide generality to the phenomenon of collaborative inhibition and can be explained by invoking concepts of strategy disruption and source monitoring.
\end{abstract}

Collaborative remembering occurs when people work together to remember an event. Such remembering occurs frequently in life, as when a family remembers a vacation, or at alumni reunions when people remember the good old days of college or high school. Prior research has focused almost entirely on collaborative processes in younger adults and, to a lesser extent, similar processes in older adults. However, remarkably little research has examined age differences in collaborative processes between younger and older adults.

The purpose of the present study was to explore possible age differences in collaborative memory performance. We examined the effects of prior collaboration on performance in younger and older adults as a function of retrieval condition (type of test and type of instruction). Subjects first took a collaborative test and then, later, a test given in isolation, to ascertain whether any effects of collaboration would be removed when people were tested individually. However, before considering our new research in detail, we next will set the stage by reviewing relevant research conducted on aging and collaborative memory.

Prior research on aging and collaboration has revealed contradictory findings, ones that can be partly explained by a difference in whether collaboration is examined at the group level or the individual level (for reviews, see Dixon, 1996; Weldon, 2001). At the group level, the combined output of a collaborative group is compared with the performance of a single individual. Dixon and his colleagues (e.g., Dixon, 1996, 1999; Gould, Trevithick, \& Dixon, 1991) have shown that collaboration, as measured at the group level, benefits older adults' retention for previously studied material, relative to individual performance. That is, groups of older adults perform better than individual older adults in recalling a total set of previously experienced events. Dixon has argued that the items produced by other people can act as retrieval cues, so that collaboration causes veridical performance to increase and errors to decline (Dixon, Gagnon, \& Crow, 1998). The group collaborative work is important in highlighting factors related to successful collaboration and demonstrating that older adults can effectively collaborate on a task. However, the group collaborative work does not answer questions concerning the relative impact of collaboration on each individual's performance.

Studies that have measured the effect of collaboration on an individual level have shown that individuals' performance is negatively affected by collaboration, a finding contrary to the group work discussed above. Measuring

M. L. Meade, mlmeade@montana.edu 
the effect of collaboration on an individual level relies on the concept of nominal groups. Nominal group recall refers to the pooled unique items produced by individuals who performed on their own. If one assumes that collaboration has no effect on performance, collaborative group performance should be equivalent to the pooled performance of individuals. Yet many studies have demonstrated that collaborative groups do not produce as many items as pooled nominal groups, suggesting that collaboration disrupts individuals' retrieval (e.g., Andersson \& Rönnberg, 1996; B. H. Basden, Basden, Bryner, \& Thomas, 1997; Weldon \& Bellinger, 1997; Wright \& Klumpp, 2004). This counterintuitive finding of process loss (cf. Steiner, 1972) for individuals working in collaborative groups is referred to as collaborative inhibition (Bouchard \& Hare, 1970; Weldon \& Bellinger, 1997).

Collaborative inhibition is well established in younger adults (see Harris, Paterson, \& Kemp, 2008, for a review), yet only a few studies have examined the effect in older adults. Johansson, Andersson, and Rönnberg (2000) gave older adults a tour of a college campus and obtained collaborative inhibition for both retrospective and prospective memory performance related to the tour. Ross, Spencer, Linardatos, Lam, and Perunovic (2004) found evidence of collaborative inhibition among older adults for items correctly recalled from a shopping list and also for items falsely recalled from the list (suggesting fewer memory errors in collaborative groups, relative to nominal groups). Johansson, Andersson, and Rönnberg (2005) obtained collaborative inhibition among older adult couples utilizing ineffective strategies on a recall test (e.g., low agreement on how to divide responsibility for the list items) but also found marginal collaborative facilitation for couples utilizing effective strategies (e.g., high agreement on how to divide responsibility). Importantly, none of the studies above included a younger adult comparison group, so it is unknown whether older adults show a different effect of collaboration, relative to younger adults.

One recent study by Ross, Spencer, Blatz, and Restorick (2008) provided a strong test of age differences in collaborative recall by examining the role of younger couples (married an average of 8 years) and older adult couples (married an average of 51 years) on a collaborative memory task. Ross et al. (2008) demonstrated collaborative inhibition on veridical memory performance for younger and older adults and further suggested that, for false recall, collaboration may benefit both younger and older adults by allowing for error correction (i.e., groups are more accurate than individuals because members of groups can correct one another's errors as they give responses). Most relevant to the present study was the finding of no interaction between age and collaboration, suggesting that the magnitude of collaborative inhibition was generally equivalent for younger and older adults (with the usual proviso about caution in accepting a null hypothesis). Critically, however, both younger and older adults in Ross et al.'s (2008) study were married couples with years of practice remembering together.

Research with younger adults suggests that partners who know each other well suffer less collaborative inhibi- tion than do strangers. Andersson and Rönnberg (1995, 1996) demonstrated that collaborative inhibition was obtained among unacquainted pairs but was reduced among pairs of good friends. Johansson et al. (2005) found a similar trend in older adult couples, although the difference in collaborative inhibition between older adult married couples and unacquainted pairs did not reach statistical significance (see also Gould, Osborn, Krein, \& Mortenson, 2002, for a group-level analysis of partner familiarity in older adults).

In the present research, we asked about age differences among unacquainted partners, to follow the paradigm used in most research on collaborative inhibition in younger adults. In addition, we also employed three manipulations thought to differentially affect collaboration and age: the retrieval condition used in testing collaborative groups (free- and forced-report cued recall and free recall), whether any effects of collaboration would remain when individuals were subsequently tested alone, and the propensity to commit errors across retrieval conditions (to see whether collaboration would reduce or increase errors). We will consider each variable in turn and provide the rationale for including it.

\section{Retrieval Conditions}

Collaborative inhibition has been obtained across a variety of retrieval conditions, including free recall (e.g., Weldon \& Bellinger, 1997) and forced recall, the latter of which requires subjects to guess to a prescribed number of responses (Weldon, Blair, \& Huebsch, 2000). Interestingly, however, collaborative inhibition has not consistently been obtained on tests of cued recall. B. H. Basden et al. (1997) obtained collaborative inhibition on cued recall tests of categorized word lists when the names of all the categories were presented simultaneously and subjects were free to recall from the categories in any order. However, they did not obtain collaborative inhibition when category names were presented sequentially and subjects were required to exhaust recall from a given category before recalling from the next one. Such differences in obtaining collaborative inhibition under these retrieval conditions may be explained by the retrieval strategy disruption hypothesis (B. H. Basden et al., 1997). This term refers to the hypothesis that an individual's natural retrieval order is interrupted in collaborative situations with little structure, which may explain why collaborative inhibition occurs: The individual's organizational scheme for retrieval is derailed when others are responding with their recollections. Although few direct comparisons exist, one hypothesis may be that cued recall with category name cues in a strict order may reduce collaborative inhibition by providing collaborators with an organizational scheme to guide retrieval (although see Ross et al., 2008, for an exception). When collaborators are free to use the category names in any order, the disruption between partners may occur.

The present experiments compared as directly as possible collaborative inhibition on tests of free-report cued recall, forced-report cued recall, and free recall for subjects of different ages. Previous investigators have used one or another of these measures but have not compared 
them. Consistent with the retrieval strategy disruption hypothesis, collaborative inhibition effects may be smaller when greater retrieval support is provided (cf. B. H. Basden et al., 1997). On the other hand, providing cues may sometimes further disrupt a natural retrieval order (D. R. Basden \& Basden, 1995). We might expect age to exaggerate the effects of retrieval condition, because age differences are minimized with greater retrieval support and we are using both free and cued recall (e.g., Balota, Dolan, \& Duchek, 2000; Craik, 1983; Craik \& McDowd, 1987). We predict that age differences in collaborative recall will be minimal on tests of cued recall and will be greatest on tests of free recall. In addition, we compared two versions of cued recall. In free-report cued recall, subjects are instructed to recall an item to a cue only if they are reasonably sure it occurred during study; in forced-report cued recall, subjects must respond with a response to every cue, even if they have to guess (see Koriat \& Goldsmith, 1996, for a discussion of report options in memory experiments).

\section{Testing of Individual Recall After Collaborative Recall}

Another variable of interest in the present project is the effect that prior collaboration has on subsequent individual memory performance. Many studies have examined this question, with results suggesting that prior collaboration may result in an advantage on later individual recall, especially if two successive collaborative recalls are completed (Blumen \& Rajaram, 2008). B. H. Basden, Basden, and Henry (2000) demonstrated that even though collaborative inhibition occurred on an initial test of categorized lists, there were benefits from prior collaboration on later individual recall. At the very least, there may be no lasting effect of collaborative inhibition, so that when the distracting collaborator is removed, individuals are able to regain access to the information lost previously to collaborative inhibition (Finlay, Hitch, \& Meudell, 2000). Although this pattern has occurred in prior studies with younger adults, none of the previous studies included older adult samples. Can older adults also shed inhibition from prior collaborations and regain access to lost items on a delayed individual test? There are reasons in the prior literature to expect that the answer to this question will be no.

Using a standard individual memory paradigm, Henkel (2007) demonstrated that older adults show a smaller increase in accuracy across repeated tests than do younger adults and also produce more errors across repeated retrievals, relative to younger adults. Regarding collaboration, it seems likely that older adults will be differentially affected by prior collaboration on subsequent individual testing because they are generally more susceptible to interference effects (Kane \& Hasher, 1995), have trouble with certain aspects of source monitoring (e.g., Hashtroudi, Johnson, \& Chrosniak, 1989; McIntyre \& Craik, 1987), and have reduced recollective abilities (e.g., Jacoby, Jennings, \& Hay, 1996; Jennings \& Jacoby, 1997). Such cognitive deficits may make it especially difficult for older adults to determine whether an item remembered from the initial test occurred in the study episode or was suggested by a collaborator. Furthermore, the relative difficulty of distinguishing the original study episode from the initial collaborative recall episode should vary as a function of retrieval condition, with older adults being especially disadvantaged on individual recall tests following forced recall (Meade \& Roediger, 2006; see also Ackil \& Zaragoza, 1998; Roediger, Wheeler, \& Rajaram, 1993). Note that the majority of prior studies on repeated testing have been conducted on standard list-learning memory paradigms (although see Ross et al., 2008, for an exception). As was noted by Rajaram and Pereira-Pasarin (2007), collaboration may serve to exaggerate the tendencies of individual recall, so that collaboration in standard memory paradigms may lead to increased levels of accurate recall on subsequent individual tests but collaboration in paradigms designed to induce false memories (such as the Deese/ Roediger-McDermott [DRM] paradigm; Deese, 1959; Roediger \& McDermott, 1995; see below) may lead to increased levels of false recall on subsequent individual memory tests. This consideration leads to the third concern in our experiments.

\section{False Recall}

Collaborative memory studies generally compare individual and group performances in terms of total number of items correctly remembered (intrusions may be mentioned but are usually not the main focus of the experiments). However, one study by B. H. Basden, Basden, Thomas, and Souphasith (1998) directly examined false recall in collaborative groups, using the DRM associative word paradigm in which students study word lists in which study items (bed, rest, awake, dream ...) are highly associated to a word that is not presented (sleep). The finding is that sleep is often falsely recalled and falsely recognized as if it were a list member (see Gallo, 2006, for a comprehensive review). B. H. Basden et al. (1998) found no collaborative inhibition for false recall for associated word lists but did find evidence of collaborative inhibition for the most common exemplars of categorized lists, ones that were not presented in the lists during study. Furthermore, B. H. Basden et al. (1998) found a greater overall intrusion rate for collaborative groups, relative to nominal groups, and they suggested that because the collaborative task involved taking turns to provide answers, individuals in the collaborative group might feel pressure to participate in recall and so lower their response threshold (cf. Perlmutter, 1953). These findings are directly contradictory to the collaborative error correction process outlined by Ross and colleagues (Ross et al., 2008; Ross et al., 2004), which suggests that collaborative groups are more accurate than nominal groups because one member can correct another member's error. Critically, the collaborative task in Ross et al.'s (2008) study was unstructured, so that individuals in the collaborative group could recall items at any time and so had potentially greater opportunity to interact with each other and correct errors (in contrast to the turn-taking procedure implemented by B. H. Basden et al., 1998).

Thorley and Dewhurst (2007) demonstrated that the specific procedure of the collaborative task used by various researchers differentially influences memory errors in 
collaborative memory tasks. Briefly, subjects in a collaborative memory task may be asked to take turns recalling items (turn-taking recall, as used in B. H. Basden et al., 1998), or subjects may be allowed to recall in any order (unstructured recall, as used in Ross et al., 2008). Thorley and Dewhurst obtained greater false recall for associated word lists among turn-taking collaborators than among unstructured collaborators, thus providing evidence that taking turns during collaboration increases subjects' pressure to respond - hence, leading to more errors. The present experiments employed a turn-taking procedure that minimizes discussion of items as they are recalled and so should elicit minimal, if any, error correction. Consistent with the findings of B. H. Basden et al. (1998) and Thorley and Dewhurst (2007), we predicted that collaborating pairs would produce more intrusions of erroneous items than would individuals recalling on their own. Also consistent with Thorley and Dewhurst, we predicted that errors produced initially in collaborative groups would carry over to subsequent individual tests, especially among older adults (for related studies, see Meade \& Roediger, 2002; Roediger, Meade, \& Bergman, 2001).

Finally, because older adults demonstrate disproportionately greater false memory following tests of forced recall, relative to cued recall (Meade \& Roediger, 2006), we expected that false recall would be greatest on a second test following prior collaborative forced-report cued recall, because older adults may have an especially difficult time distinguishing items that were on the study list from items they or their partners produced under forced-report cued recall.

The present experiment extends previous work by directly comparing unacquainted younger and older adults on tests of both free-report cued recall and forced-report cued recall (free recall was explored in Experiment 2). We relied on a categorized list paradigm developed by Meade and Roediger (2006; for related paradigms, see B. H. Basden et al., 1998; Smith, Ward, Tindell, Sifonis, \& Wilkenfeld, 2000) that elicits reliable false recall on both freereport and forced-report cued recall tests and also elicits higher false recall for older adults, relative to younger adults, when they are tested individually. Of interest is whether collaboration may differentially affect younger and older adults across different types of retrieval instructions for veridical and false recall and whether any lasting effects of collaboration will occur on younger and older adults' subsequent individual memory performance.

\section{EXPERIMENT 1}

\footnotetext{
Method

Subjects. The subjects were 40 Washington University undergraduates (age range, $18-25$ years; $M=19$ ) and 40 older adults (age range, 67-88 years; $M=77$ ) recruited from the St. Louis community. Older adults were selected from a population with a mean score of 35 (range, 26-39) on the Shipley vocabulary test (Shipley, 1946), which is typically somewhat higher than young adults score (see Meade \& Roediger, 2006, for additional details). Young adults participated in the experiment for partial fulfillment of a class requirement; older adults were compensated $\$ 10 / \mathrm{h}$. Data from the young and older adults in the individual recall condition in Experi-
}

ment 1 were obtained from the same subjects whose data were previously published (Meade \& Roediger, 2006). However, the analyses in the earlier article were scored differently and used for different purposes. In the present analyses, the individuals' data for Recall Test 1 were paired, and nominal group scoring was used; and across all tests, individual recall conditions were compared with the collaborative recall conditions.

Design. The experiment consisted of a $2 \times 2 \times 2$ betweensubjects design. Retrieval group (individual or collaborative) and retrieval condition (forced-report cued recall or free-report cued recall) and age (younger or older adults) were all manipulated between subjects. The primary dependent variables were veridical recall and recognition of the list items and false recall and recognition of the critical items.

Materials. Materials were selected from Meade and Roediger (2006) and consisted of six categorized lists constructed from the Battig and Montague (1969) norms. Each list was constructed from a single category and contained exemplars numbered 6-22 of a given category, for a total of 17 items. Exemplars 1-5 of each category were excluded from the lists and designated as critical items. The recognition source-monitoring test included 90 items (the 5 critical items from each list, 5 studied items from each list, and 30 unrelated filler items).

Procedure. The subjects were tested individually or with 1 other subject of the same age group. The subjects were visually presented (by computer) with six categorized word lists and were asked to study each list item in preparation for a memory test. The lists were presented in blocked fashion (17 items from the category, presented sequentially) but were not preceded by the category name. Each item was presented on a computer screen for $1.5 \mathrm{sec}$. At the completion of each category list, the computer prompted the subject to press the enter key to begin the next list. After all six lists had been presented, the subjects completed a 3-min filler task. The subjects were next asked to orally recall as many words as possible from the word lists while an experimenter recorded their responses. The experimenter provided the verbal label of each list (the category name), and the subjects then recalled items from that list only. The subjects recalled either individually or collaboratively; collaborative pairs took turns recalling items. We adopted a turn-taking procedure, rather than an unstructured test, during collaboration to increase the subjects' pressure to respond and, thus, elicit higher error rates (cf. Thorley \& Dewhurst, 2007).

The subjects in the free-report cued recall condition were given category names and were asked to recall as many items as possible without guessing. When the subjects in the individual free-report cued recall condition had exhausted recall for a given category, they were allowed to move on to the next list, regardless of how many items had been recalled. In the collaborative free-report cued recall condition, the subjects were allowed to pass their turn when they could think of no more items, and the other person was allowed to continue until he or she could also produce no new items.

The subjects in the forced-report cued recall condition were also given category names but were required to come up with 20 items from each list (only 17 were actually presented). The subjects in the individual forced-report cued recall condition were required to produce all 20 items on their own, whereas the subjects in the collaborative forced-report cued recall condition were required to produce 10 each (for a total of 20 , so that we could compare individuals recalling 20 items on their own with individuals recalling 20 items in a pair). Partners in the collaborative forced-report cued recall condition were not allowed to pass on their turns; each subject was required to produce one response. We chose to examine forced-report cued recall because we were interested in the effect of collaboration on both veridical and false recall. By requiring the subjects to produce more items than were actually presented, we ensured high error rates so as to better examine any influence of collaboration on false recall on the individual tests given later.

Following initial recall, the subjects were asked to recall the word lists a second time, but this time, all the subjects were tested indi- 
vidually, with instructions to remember list items as well as possible but not to guess (i.e., typical free-report cued recall instructions). The subjects were provided with the category name and had $3 \mathrm{~min}$ per category to respond. In addition, they were asked to make remember/know judgments for each item. Following Tulving (1985), Gardiner (1988), and Rajaram (1993), the subjects were instructed that remember responses indicated that they had a specific recollection about the item. Know responses indicated that the item had been studied in the list but elicited no specific recollective details. All the subjects indicated that they understood the distinction between remember and know judgments before proceeding.

In the final phase of the experiment, the subjects individually completed the source-monitoring recognition test that required them to indicate whether each item had appeared in the study list (a list judgment), whether they had said it aloud during the initial recall test (a self judgment), or whether the item had not previously been presented in the context of the experiment (neither). The subjects were told that they could indicate multiple sources for an item-for example, by indicating that an item had occurred in the study list (list) and that they had recalled it previously (self). The subjects in the collaborative condition had the additional option of indicating that their partners had recalled the item previously (other). We chose to include the final source-monitoring recognition test to determine whether the subjects could reduce memory errors if attention were drawn to the possible sources of information (cf. Multhaup, 1995). Finally, all the subjects were fully debriefed on the purpose of the experiment.

\section{Results}

Recall Test 1. Table 1 presents the mean proportions of list items and critical items recalled in the first recall test as a function of age of subjects, individual versus collaborative test conditions, veridical recall (proportion recalled of the 17 list items per category), and critical item recall (proportion recalled of the 5 missing items from each category). The latter quantity indicates false recall in the free-report conditions. Numbers are pooled across individuals to determine whether collaborative inhibition was obtained in the present paradigm. In the collaborative condition, pooled recall was simply the total output of the group, but for individuals, any item independently recalled by both people was counted only one time (i.e., we used nominal groups for comparison, as is standard in these comparisons). Effect sizes $\left(\eta^{2}\right)$ were also computed for main effects and interactions. According to Cohen (1988), small effect sizes correspond to $\eta^{2}<.06$, medium effect sizes correspond to $.06<\eta^{2}<.14$, and large effect sizes correspond to $\eta^{2}>$.14. Statistical significance was set at $p \leq .05$, unless otherwise noted.

Table 1

Mean Proportions of Pooled Items Recalled by Younger and Older Adults on an Individual or Collaborative Free-Report Cued Recall or Forced-Report Cued Recall Test (Experiment 1, $N=\mathbf{8 0}$ )

\begin{tabular}{lccccc}
\hline & \multicolumn{2}{c}{$\begin{array}{c}\text { Free-Report } \\
\text { Cued Recall }\end{array}$} & & \multicolumn{2}{c}{$\begin{array}{c}\text { Forced-Report } \\
\text { Cued Recall }\end{array}$} \\
\cline { 2 - 3 } \cline { 5 - 6 } & Younger & Older & & Younger & Older \\
\hline List Recall & & & & & \\
Individual & .60 & .61 & & .85 & .78 \\
Collaborative & .49 & .49 & & .74 & .66 \\
Critical Recall & & & & & \\
Individual & .17 & .43 & & .88 & .90 \\
Collaborative & .15 & .43 & & .66 & .71 \\
\hline
\end{tabular}

As can be observed in Table 1, younger and older adults achieved similar levels of list recall in the free-report cued recall condition, but false recall was much higher for older adults in this condition. In the forced-report cued recall conditions, younger adults were more accurate in veridical recall and in false recall, too (i.e., younger adults produced fewer errors than did older adults in these conditions). In addition, collaborative inhibition resulted in all cases except for critical or false recall in the free-report cued recall condition. These impressions were confirmed by the statistical analyses reported next.

A 2 (collaborative or individual) $\times 2$ (free-report or forced-report cued recall) $\times 2$ (younger or older adults) ANOVA computed on list recall revealed a significant main effect of collaboration $\left[F(1,32)=26.23, M S_{\mathrm{e}}=\right.$ $\left..01, \eta^{2}=.45\right]$. The pooled list recall of subjects recalling on their own $(M=.71)$ was significantly greater than the pooled recall of subjects recalling together in pairs $(M=$ .59), replicating the standard effect of collaborative inhibition. Importantly, the ANOVA revealed no interaction between age and collaboration $(F<1)$, suggesting that the magnitude of the collaborative inhibition effect was similar for younger and older adults.

There was also a significant main effect of retrieval condition $\left[F(1,32)=81.17, M S_{\mathrm{e}}=.01, \eta^{2}=.72\right]$. The subjects in the forced-report cued recall condition produced a significantly greater number of list items $(M=$ .76) than did the subjects in the free-report cued recall condition $(M=.54)$. Although this result is inconsistent with past research that generally has shown no difference in hit rates between free and forced recall (e.g., Roediger \& Payne, 1985), the inconsistency may be explained in terms of list type; the present experiment used categorized lists, whereas past research has often used lists of unrelated items (for discussions, see Erdelyi, Finks, \& FeiginPfau, 1989; Ritter \& Buschke, 1974; Roediger, Srinivas, \& Waddill, 1989). Of course, many apparently correct items on the forced recall test may have been due to guessing, because the same pattern occurred for critical items.

Interestingly, we found no main effect of age on recall of list items $(F<1.4, p>.05)$, most likely because of the strong retrieval cues (category names) present at recall (cf. Balota et al., 2000; Craik, 1983; Craik \& McDowd, 1987). Although this is somewhat surprising with our long lists, this outcome actually helps to make results comparing older and younger adults on subsequent tests more interpretable because they are not compromised by large differences on the initial tests that might carry over to later tests.

Proportions of the 5 critical items recalled were analyzed by a separate 2 (collaborative or individual) $\times$ 2 (free-report or forced-report cued recall) $\times 2$ (younger or older adults) ANOVA. As in veridical recall, we obtained collaborative inhibition; pooled groups produced a greater number of false alarms $(M=.60)$ than did collaborative groups $(M=.49)\left[F(1,32)=7.65, M S_{\mathrm{e}}=.02\right.$, $\left.\eta^{2}=.19\right]$. However, this effect of collaboration on false recall was tempered by a significant interaction between collaboration and retrieval condition $[F(1,32)=5.94$, $\left.M S_{\mathrm{e}}=.02, \eta^{2}=.16\right]$. No collaborative inhibition was 
obtained for critical items under free-report cued recall instructions $(t<1, p>.05)$. Collaborative inhibition for critical items was found only in forced-report cued recall $[M=.69$ for collaborative groups, $M=.89$ for pooled individuals; $t(18)=3.80, S E M=.07]$, possibly due, in part, to the fact that our forced-report procedure required each subject in the individual condition to produce 20 items and each subject in the collaborative groups to produce 10 items each. Importantly, collaboration did not interact with age $(F<1, p>.05)$, again suggesting that collaboration exerts similar effects on younger and older adults.

Finally, the main effect of age for critical items was significant $\left[F(1,32)=15.03, M S_{\mathrm{e}}=.02, \eta^{2}=.32\right]$, as was the interaction between age and retrieval condition $\left[F(1,32)=9.11, M S_{\mathrm{e}}=.02, \eta^{2}=.22\right]$. This outcome suggests that older adults produced more critical items than did younger adults only in the free-report cued recall condition $[t(18)=3.80, S E M=.07]$ with its instruction warning against guessing. There was no age difference in the proportion of critical items produced by younger and older adults in the forced-report cued recall condition $(t<$ $0.65, p>.05$ ), a finding that makes sense given that all the subjects were forced to guess.

Recall Test 2. Table 2 presents the mean proportion of list and critical items recalled on the second recall test, which was recall of individual subjects, as well as the mean proportion of remember and know responses. Mean total recall is presented in bold in Table 2, with remember and know responses presented in normal typography. The overall data will be discussed first, and then the remember/ know data will be described in a later section. Keep in mind that the second recall test was always taken individually under free-report cued recall instructions (i.e., with instructions not to guess). The condition labels on the table (e.g., prior individual or prior collaborative) refer to the first recall test condition, because we were interested in whether lasting effects of collaboration and/or retrieval condition would appear on individuals' subsequent recall

Table 2

Mean Proportions of Nonpooled Items Recalled on Subsequent Individual Cued Recall Test (Experiment 1, $N=80$ )

\begin{tabular}{|c|c|c|c|c|}
\hline & \multicolumn{2}{|c|}{$\begin{array}{l}\text { Prior Free-Report } \\
\text { Cued Recall }\end{array}$} & \multicolumn{2}{|c|}{$\begin{array}{c}\text { Prior Forced- } \\
\text { Report Cued Recall }\end{array}$} \\
\hline & Younger & Older & Younger & Older \\
\hline \multicolumn{5}{|l|}{ List Recall } \\
\hline Prior individual & .48 & .43 & .51 & .51 \\
\hline Remember & .39 & .34 & .40 & .37 \\
\hline Know & .09 & .09 & .12 & .14 \\
\hline Prior collaborative & .42 & .38 & .52 & .46 \\
\hline Remember & .30 & .26 & .39 & .35 \\
\hline Know & .12 & .12 & .13 & .11 \\
\hline \multicolumn{5}{|l|}{ Critical Recall } \\
\hline Prior individual & .17 & .28 & .32 & .60 \\
\hline Remember & .06 & .16 & .04 & .33 \\
\hline Know & .11 & .12 & .28 & .27 \\
\hline Prior collaborative & .19 & .39 & .30 & .58 \\
\hline Remember & .07 & .26 & .08 & .32 \\
\hline Know & .12 & .13 & .22 & .26 \\
\hline
\end{tabular}

Note-Boldface indicates mean total recall. tests. Accordingly, all the proportions in this table reflect mean individual recall, not pooled recall.

The results from individual list recall in Table 2 show that collaborative inhibition was removed on the second test and age differences were minimized, too. A 2 (prior collaborative or individual) $\times 2$ (prior free-report or forced-report cued recall) $\times 2$ (younger or older adults) ANOVA on list items revealed no main effect of collaboration $(F<2.4, p>.05)$. This disappearance of collaborative inhibition is consistent with B. H. Basden et al.'s (2000) findings. No age differences were obtained, nor was there any interaction between collaboration and age $(F \mathrm{~s}<2.5, p \mathrm{~s}>.05)$, suggesting that collaboration had no lasting effect for younger or older adults' later recall of list items. On the other hand, the main effect of retrieval condition was significant $\left[F(1,72)=9.70, M S_{\mathrm{e}}=.01\right.$, $\left.p<.01, \eta^{2}=.12\right]$. Once the subjects were forced to recall items on the first recall test, they produced a higher proportion of list items when tested at a later time $(M=.50)$ than did the subjects previously tested in the free-report cued recall condition $(M=.43)$.

Analyzing critical (false) recall on the second recall test, a 2 (prior collaborative or individual) $\times 2$ (prior free-report or forced-report cued recall) $\times 2$ (younger or older adults) ANOVA revealed no main effect of collaboration and no interaction between collaboration and age $(F \mathrm{~s}<1, p \mathrm{~s}>.05)$. The collaborative inhibition present for critical items in the first recall test disappeared in the second recall test for both younger and older adults. The ANOVA also revealed a main effect of prior retrieval condition $\left[F(1,72)=21.33, M S_{\mathrm{e}}=.04, \eta^{2}=.23\right]$. The subjects were more likely to recall critical items on Recall Test 2 (with instructions not to guess) if they had previously recalled under forced-report cued recall instructions than if they had previously recalled under free-report cued recall instructions. In addition, the main effect of age was significant $\left[F(1,72)=26.99, M S_{\mathrm{e}}=.04, \eta^{2}=\right.$ .27], revealing that older adults recalled more false items on the subsequent recall test $(M=.46)$ than did younger adults $(M=.25)$. As was suggested by Meade and Roediger (2006), this may be explained by source-monitoring deficits (Johnson, Hashtroudi, \& Lindsay, 1993) in older adults that made it more difficult for them to distinguish which of the previously recalled items had actually been presented in the list and which items they themselves or the other subject had falsely generated.

Remember and know responses. For each item recalled on the second recall test, the subjects were asked to indicate whether they remembered the item as having occurred in the list or whether they knew it had occurred in the list. Remember/know responses were made concurrently with recall, so the subjects assigned judgments as they recalled each item. Table 2 shows remember/know results decomposed under total recall for the various conditions in the nonbold typography.

Separate 2 (prior collaborative or individual) $\times$ 2 (younger or older adults) $\times 2$ (prior free-report or forcedreport cued recall) ANOVAs were computed on remember and know responses for list items. The ANOVAs revealed no significant differences in remember responses for any 
Table 3

Mean Proportions of List Recognition on a Subsequent Individual Recognition Test (Experiment $1, N=80$ )

\begin{tabular}{|c|c|c|c|c|}
\hline \multirow[b]{2}{*}{ List Recognition } & \multicolumn{2}{|c|}{$\begin{array}{l}\text { Prior Free-Report } \\
\text { Cued Recall }\end{array}$} & \multicolumn{2}{|c|}{$\begin{array}{l}\text { Prior Forced- } \\
\text { Report Cued } \\
\text { Recall }\end{array}$} \\
\hline & Younger & Older & Younger & Older \\
\hline \multicolumn{5}{|c|}{ Prior Individual } \\
\hline List only & .42 & .37 & .29 & .29 \\
\hline Both list and self & .46 & .45 & .58 & .62 \\
\hline Total correct recognition & .88 & .82 & .87 & .91 \\
\hline Self & .02 & .06 & .06 & .04 \\
\hline Neither & .10 & .12 & .07 & .05 \\
\hline \multicolumn{5}{|c|}{ Prior Collaborative } \\
\hline List only & .35 & .25 & .17 & .17 \\
\hline Both list and self or other & .46 & .43 & .70 & .68 \\
\hline Total correct recognition & .81 & .68 & .87 & .85 \\
\hline Self or other & .02 & .06 & .07 & .08 \\
\hline Neither & .17 & .26 & .06 & .07 \\
\hline
\end{tabular}

of the factors $(F \mathrm{~s}<3.3, p \mathrm{~s}>.05)$. The ANOVA computed on know responses revealed a significant main effect only for retrieval condition $\left[F(1,72)=4.29, M S_{\mathrm{e}}=.01, \eta^{2}=\right.$ $.06]$. The subjects were more likely to say that they knew that a list item had been in the list when they had previously recalled under forced-report cued recall instructions than when they had previously recalled under free-report cued recall instructions. Main effects for collaboration and age were not significant $(F \mathrm{~s}<0.56, p \mathrm{~s}>.05)$.

Remember and know responses were also analyzed for critical items, using separate 2 (prior collaborative or individual) $\times 2$ (prior free-report or forced-report cued recall) $\times 2$ (younger or older adults) ANOVAs. The ANOVA for remember responses revealed a significant main effect of age $\left[F(1,72)=29.02, M S_{\mathrm{e}}=.03, \eta^{2}=.29\right]$. Older adults were more likely than were younger adults to say that they remembered that a critical item had occurred in the list $[t(78)=5.38, S E M=.04]$, confirming prior studies showing greater false remembering in older adults than in younger adults. The proportion of remember responses did not vary in relation to prior test condition $(F \mathrm{~s}<2.06$, $p \mathrm{~s}>.05$ ). A separate ANOVA conducted on know responses to critical items showed a significant main effect of prior retrieval condition $\left[F(1,72)=15.96, M S_{\mathrm{e}}=.02\right.$, $\left.\eta^{2}=.18\right]$. The subjects were more likely to indicate that they knew that a critical item had been presented in the study list following prior forced-report cued recall than following free-report cued recall. No significant main effects were found for collaboration or age $(F \mathrm{~s}<0.25, p \mathrm{~s}>$ $.05)$.

Recognition/source-monitoring test. Tables 3 and 4 display the mean proportion of list items correctly recognized and critical items falsely recognized by the subjects as a function of prior test condition. Correct recognition scores reflect the proportion of times the subjects attributed studied items as having been presented in the study list (the sum of list responses and list-and-self responses for list items (list-and-other responses were also included for the collaborative groups). False recognition scores reflect the proportions of times the subjects attributed criti- cal items as having been presented in the study list (the sum of list responses and list-and-self responses for critical items; list-and-other responses were also included for the collaborative groups). The recognition test was always taken individually, and of course, the results here may be affected by the two prior recall tests.

Examining list recognition, a 2 (prior free-report or forced-report cued recall) $\times 2$ (prior collaborative or individual) $\times 2$ (younger or older adults) ANOVA revealed a marginal effect of collaboration $\left[F(1,72)=3.65, M S_{\mathrm{e}}=\right.$ $\left..02, p=.06, \eta^{2}=.05\right]$, suggesting a trend consistent with collaborative inhibition, but no interaction between prior collaboration and any other variables $(F \mathrm{~s}<1, p \mathrm{~s}>.05)$, suggesting that collaboration had similar effects on both younger and older adults in both retrieval conditions. The ANOVA did reveal a main effect of retrieval condition $\left[F(1,72)=4.82, M S_{\mathrm{e}}=.02, \eta^{2}=.06\right]$; the subjects who had initially recalled the list items under forced-report cued recall instructions had higher hit rates than did the subjects who previously recalled the list under free-report cued recall instructions. Finally, the ANOVA revealed no age differences in list recognition $(F<1.6, p>.05)$.

Table 4 presents the recognition data for younger and older adults' recognition of critical items. Keep in mind that none of these 30 items were presented in the list, so these large values represent high rates of false recognition. A 2 (younger or older adult) $\times 2$ (prior free-report cued recall or forced-report cued recall $) \times$ 2 (prior collaborative or individual) ANOVA showed that older adults falsely recognized significantly more critical items than did younger adults $[F(1,72)=15.07$, $\left.M S_{\mathrm{e}}=.06, \eta^{2}=.18\right]$. However, there was no main effect of prior collaboration on false recognition and no interaction between collaboration and age $(F \mathrm{~s}<1, p \mathrm{~s}>$ $.05)$. Finally, the ANOVA revealed that false recognition was higher for the subjects who had previously recalled under forced-report cued recall instructions than for the subjects who had previously recalled under free-report cued recall instructions $\left[F(1,72)=4.33, M S_{\mathrm{e}}=.06\right.$, $\left.\eta^{2}=.06\right]$. This pattern was exaggerated for older adults,

Table 4

Mean Proportions of Critical Recognition on a Subsequent Individual Recognition Test (Experiment $1, N=80$ )

\begin{tabular}{|c|c|c|c|c|}
\hline \multirow[b]{2}{*}{ Critical Recognition } & \multicolumn{2}{|c|}{$\begin{array}{c}\text { Prior Free-Report } \\
\text { Cued Recall }\end{array}$} & \multicolumn{2}{|c|}{$\begin{array}{l}\text { Prior Forced- } \\
\text { Report Cued } \\
\text { Recall }\end{array}$} \\
\hline & Younger & Older & Younger & Older \\
\hline \multicolumn{5}{|c|}{ Prior Individual } \\
\hline List only & .43 & .35 & .16 & .17 \\
\hline Both list and self & .16 & .28 & .37 & .66 \\
\hline Total false recognition & .59 & .63 & .53 & .83 \\
\hline Self & .01 & .05 & .33 & .10 \\
\hline Neither & .40 & .33 & .13 & .07 \\
\hline \multicolumn{5}{|c|}{ Prior Collaborative } \\
\hline List only & .35 & .31 & .18 & .17 \\
\hline Both list and self or other & .17 & .32 & .39 & .77 \\
\hline Total false recognition & .52 & .63 & .57 & .94 \\
\hline Self or other & .06 & .04 & .26 & .01 \\
\hline Neither & .42 & .33 & .17 & .05 \\
\hline
\end{tabular}


as indicated by a significant age $\times$ retrieval condition interaction $\left[F(1,72)=4.58, M S_{\mathrm{e}}=.06, \eta^{2}=.06\right]$. Older adults were more likely to false alarm on the recognition test after recalling under forced-report cued recall instructions $(M=.88)$, relative to free-report cued recall instructions $(M=.65)[t(38)=4.40, S E M=.06]$. False recognition rates for younger adults did not vary in relation to prior recall condition ( $t \mathrm{~s}<1, p \mathrm{~s}>.05)$, averaging around 60 .

\section{Discussion}

The results of Experiment 1 demonstrated that collaborative inhibition for list items occurred for both younger and older adults on an initial test of free-report cued recall and forced-report cued recall. Collaborative inhibition for critical items was obtained only on an initial test of forcedreport cued recall (not free-report cued recall). There were no age differences in the magnitude of the collaborative inhibition effect for list or critical items, and collaborative inhibition disappeared on subsequent individual cued recall and recognition tests.

No age differences were found for list items in recall or recognition, although due to our methods, we could not correct recall rates on the recall tests or hit rates on the recognition test. Age differences might have occurred if we had been able to do that, because older adults did show higher false recall on the initial free-report cued recall test and on recall and recognition following forced-report cued recall, although these effects did not interact with collaboration. In Experiment 2, the lists were modified so that the same items were counterbalanced across studied and nonstudied lists, allowing us to correct recall and recognition scores for guessing.

\section{EXPERIMENT 2}

In Experiment 1, we used procedures that are atypical in the study of collaborative inhibition - namely, cued recall under free- or forced-report conditions. In Experiment 2, age differences in collaborative inhibition were examined on free recall tests. Free recall instructions were predicted to exaggerate the collaborative inhibition effect because they offer less structure to organize retrieval between collaborators (cf. B. H. Basden et al., 1997) and exaggerate age differences in recall (cf. Craik \& McDowd, 1987). In addition, we altered the structure of the presented lists so as to be able to correct recall and recognition for possible constructive memory effects.

\section{Method}

Subjects. The subjects were 40 Montana State University undergraduates (mean age $=20$ years; range, $18-28$ ) who participated in the experiment for course credit and 40 older adults (mean age $=$ 74 years; range, 65-87) recruited from the Bozeman community who participated in the experiment for $\$ 10 / \mathrm{h}$. Older adults had more education ( $M=17$ years) than did younger adults ( $M=13$ years) $[t(78)=8.27, S E M=.17]$ and also had higher scores on the Shipley Vocabulary Test $(M=35)$ than did younger adults $(M=27)[t(78)=$ $8.53, S E M=.79]$. No age differences were obtained on the Mini Mental Status Exam (MMSE; Folstein, Folstein, \& McHugh, 1975) $(M=29$ for older adults; $M=28$ for younger adults; $t<1.9)$.
Design. The design was a $2 \times 2$ between-subjects design. Age (younger or older) and collaboration (individual or collaborative) were both manipulated between subjects. Dependent variables included correct and false recall on two recall tests and hit rates and false alarm rates in recognition.

Materials. Materials were selected from Meade, Roediger, and Geraci (2009) and included six lists created from the Battig and Montague (1969) category norms. The first 22 exemplars of a given category were chosen. Of these, the top 10 items were divided so that 5 items were presented and 5 items were nonpresented (critical items). Two counterbalanced lists were created so as to calculate corrected recall and recognition for these critical items (for List A, Items 1, 4, 5, 8, and 9 were critical items, and Items 2, 3, 6, 7, and 10 were presented items; for List B, Items $2,3,6,7$, and 10 were critical items, and Items $1,4,5,8$, and 9 were presented items). Because of frequent errors in categorized lists (e.g., Meade \& Roediger, 2006), some way of correcting for errors is needed. Presenting odd- or even-numbered items permits an estimate of the contributions of constructive recall effects (or guessing) from recall of the omitted set of items (see Roediger, 1973, for a correction based on similar logic). Counterbalancing the presentation of the most typical exemplars allowed recall and recognition scores to be corrected for such guessing because we could determine the likelihood that the subjects produced a given categorical exemplar when it had been studied, relative to when it had not been studied. Of course, we also acknowledge that now critical items are not solely the most common exemplars of a category, and so overall false recall rates may be lower in Experiment 2 than in Experiment 1. The remaining 12 items were all presented to the subjects so that 17 items were presented to subjects and 5 were designated nonpresented critical items. The recognition test was also selected from Meade et al. and contained 90 items (the first 10 items from the norms [presented and critical] from each list and 30 unrelated filler items).

Procedure. The procedure in Experiment 2 was the same as the procedure in Experiment 1, except for the materials and the retrieval test. As in Experiment 1, all items were presented at a rate of $1.5 \mathrm{sec}$ per item. The subjects studied all six 17-item lists, completed a 3 -min filler task, and then were given the initial recall test under individual or collaborative recall conditions. On the initial recall test, no retrieval cues were given, and the subjects were instructed to recall as many items as possible without guessing. They were told that they could recall items in any order, with the collaborative groups being told they should take turns in recalling items. For both the initial and the second recall tests, the subjects were allotted $18 \mathrm{~min}$ to recall as many items as possible from the lists in any order. Eighteen minutes were intended to be roughly equivalent to the $3 \mathrm{~min}$ per list allowed for recall in Experiment 1. Administration of the sourcemonitoring recognition test occurred as in Experiment 1. Finally, the subjects were asked to complete a demographics questionnaire, the Shipley Vocabulary Test (Shipley, 1946), and the MMSE (Folstein et al., 1975).

\section{Results}

One older adult collaborative pair was removed from the analyses due to inability to follow instructions; the analyses below are based on 20 older adults in the individual condition and 18 in the collaborative condition. Individual data were pooled for Test 1 to create nominal groups for comparison with collaborative groups, as was discussed previously.

Recall Test 1. The mean proportions of items recalled in the four conditions on the initial recall test are presented in Table 5. The proportion of total list recall includes all studied items (including the first five items from the norms that were presented) and is conceptually similar to recall of list items from Experiment 1. A 2 (individual or 
Table 5

Mean Proportions of Items Recalled From the Total List by Younger and Older Adults on an Individual or Collaborative Free Recall Test (Experiment 2, $N=78$ )

\begin{tabular}{ccc}
\multicolumn{2}{c}{ Free Recall Test (Experiment $2, \boldsymbol{N}=\mathbf{7 8})$} \\
\cline { 2 - 3 } Total List Recall & Younger & Older \\
\hline Individual & .45 & .43 \\
Collaborative & .38 & .32 \\
\hline
\end{tabular}

collaborative) $\times 2$ (younger or older adults) independent samples ANOVA computed on the proportion of total list recall revealed a main effect of collaboration $[F(1,35)=$ 7.39, $\left.M S_{\mathrm{e}}=.01, \eta^{2}=.17\right]$. Replicating Experiment 1 and consistent with the collaborative inhibition effect, pooled individual groups $(M=.44)$ recalled significantly more list items than did collaborative groups $(M=.35)$. The ANOVA further revealed no main effect of age and no interaction between age and collaboration $(F \mathbf{s}<1.5)$. Considered together, these results suggest that both younger and older adults showed similar magnitudes of collaborative inhibition.

Turning next to the production of the first 10 items from the norms, we will discuss first recall of the 5 presented items, then recall of the 5 critical items, and finally the corrected recall score that indicates the difference between presented and critical items (see Table 6). Again, the corrected recall score accounts for the fact that the subjects might have produced some of the study items by constructing (or generating or guessing) common exemplars of a given category. A 2 (individual or collaborative recall) $\times 2$ (younger or older adults) between-subjects ANOVA computed on the 5 presented items revealed a main effect of age $\left[F(1,35)=5.10, M S_{\mathrm{e}}=.02, \eta^{2}=.13\right]$, suggesting that younger adults $(M=.63)$ recalled more of these items than did older adults $(M=.52)$. Interestingly, no reliable main effect of collaboration $[F(1,35)=2.39$, $\left.M S_{\mathrm{e}}=.02, p=.13, \eta^{2}=.06\right]$ and no interaction between collaboration and age $(F<1)$ were obtained, although note that numerically, the trend is consistent with collaborative inhibition in the range of $7 \%-8 \%$ (the same as in the analysis of total list recall). The lack of a statistical effect may be due to lower power by examining recall of only 5 items rather than 17 .

Turning next to recall of five critical items from the norms, a separate 2 (individual or collaborative) $\times$ 2 (younger or older adults) between-subjects ANOVA revealed no main effects of age or collaboration and no interaction between age and collaboration $\left(F_{\mathrm{S}}<3\right)$. Possibly, restructuring our study lists resulted in floor effects for false recall. Note, however, that older adults in the collaborative condition produced the highest numerical proportion of nonpresented critical items $(M=.14)$, which may have lasting effects on subsequent individual tests. Because our procedure employed turn taking among unacquainted dyads, it is possible that the older adults felt increased pressure to respond during their turn (cf. B. H. Basden et al., 1998; Perlmutter, 1953; Thorley \& Dewhurst, 2007).

Finally, the recall of the first 10 presented and critical items permits a corrected recall score that controls for guessing of the most typical exemplars from each category. A separate 2 (individual or collaborative) $\times 2$ (younger or older adults) ANOVA computed on the corrected recall score revealed that younger adults $(M=.55)$ recalled more than did older adults $(M=.40)[F(1,35)=9.67$, $\left.M S_{\mathrm{e}}=.02, \eta^{2}=.22\right]$. The ANOVA also revealed a marginal main effect of collaboration $\left[F(1,35)=3.64, M S_{\mathrm{e}}=\right.$ $\left..02, p=.06, \eta^{2}=.09\right]$. Consistent with the collaborative inhibition effect, collaborative groups $(M=.43)$ recalled less than did pooled individual groups $(M=.52)$. Importantly, the interaction between collaboration and age was not significant $(F<1.1)$, suggesting that the magnitude of the collaborative inhibition effect was similar for both younger and older adults on a free recall test of categorized lists. This null effect is the same as that in Experiment 1, although the nonsignificant age $\times$ collaboration interaction in Experiment 2 could have been due to low power; numerically, older adults demonstrated a larger inhibition effect (.13) than did young adults (.05).

Recall Test 2. The mean proportions of items recalled on the second (free recall) test are presented in Table 7. Recall Test 2 was always taken individually. Of interest is the effect of prior collaboration on subsequent individual recall. Accordingly, the data in Table 7 reflect the responses of individual subjects (not pooled as for Recall Test 1).

A 2 (prior individual or collaborative) $\times 2$ (younger or older adults) between-subjects ANOVA conducted on total list recall revealed a main effect of age $[F(1,74)=$ $\left.13.25, M S_{\mathrm{e}}=.01, \eta^{2}=.15\right]$ but no main effect of collaboration and no interaction between collaboration and age $(F \mathrm{~s}<1)$. Younger adults $(M=.32)$ recalled significantly more than did older adults $(M=.23)$. Replicating Experiment 1 , and also consistent with previous research (e.g., Finlay et al., 2000), collaborative inhibition disappeared on subsequent testing of individuals.

The proportions of the first 10 items from the norms recalled (both presented and critical) are presented in Table 8. A separate 2 (prior individual or collaborative) $\times$

Table 6

Mean Proportions of First 10 Items From the Norms (Presented and Critical) Recalled by Younger and Older Adults on an Individual or Collaborative Free Recall Test (Experiment 2, $N=78$ )

\begin{tabular}{lcccccccc}
\hline & \multicolumn{2}{c}{5 Presented } & & \multicolumn{2}{c}{5 Critical } & & \multicolumn{2}{c}{ Corrected } \\
\cline { 2 - 3 } & Younger & Older & & Younger & Older & & Younger & Older \\
\hline Individual & .66 & .56 & & .09 & .09 & & .57 & .47 \\
Collaborative & .59 & .48 & & .07 & .14 & & .52 & .34 \\
\hline
\end{tabular}


Table 7

Mean Proportions of Nonpooled Items Recalled From the Total List and Mean Proportions of Remember and Know Responses on Subsequent Individual Free Recall Test (Experiment 2, $N=78$ )

\begin{tabular}{ccc}
\hline & \multicolumn{2}{c}{ Free Recall } \\
\cline { 2 - 3 } Total List Recall & Younger & Older \\
\hline Prior Individual & $\mathbf{. 3 1}$ & $\mathbf{. 2 3}$ \\
Remember & .25 & .20 \\
Know & .06 & .03 \\
Prior Collaborative &. $\mathbf{3 2}$ &. $\mathbf{2 3}$ \\
Remember & .26 & .18 \\
Know & .06 & .05 \\
\hline
\end{tabular}

2 (younger or older adults) ANOVA conducted on the proportion of 5 presented items recalled revealed that younger adults $(M=.50)$ recalled more than did older adults $(M=$ .35) $\left[F(1,74)=25.46, M S_{\mathrm{e}}=.02, \eta^{2}=.26\right]$. The ANOVA revealed neither a main effect of collaboration nor any interaction between collaboration and age $(F \mathbf{s}<1)$, suggesting again that there were no lasting effects of collaboration on subsequent recall of the most typical category exemplars.

Turning next to recall of the 5 critical items, a 2 (prior individual or collaborative) $\times 2$ (younger or older adults) ANOVA revealed no significant main effect of age $(F<1)$, but a significant main effect of prior collaboration $\left[F(1,74)=7.16, M S_{\mathrm{e}}=.004, \eta^{2}=.09\right]$. The subjects were more likely to falsely recall critical items if they had previously collaborated $(M=.10)$ than if they had previously recalled alone $(M=.06)$. Such a finding is consistent with Rajaram and Pereira-Pasarin's (2007) argument that collaboration might exaggerate errors in later individual recall (see also Thorley \& Dewhurst, 2007). However, it is inconsistent with the error correction process outlined by Ross et al. (2008; Ross et al., 2004) and further differs from Experiment 1's finding that prior collaboration produced no lasting effects on subsequent tests. This difference between experiments may be explained by the different retrieval demands of free recall employed in Experiment 2 and/or changes to the list structure between experiments.

Finally, the corrected recall data in the right columns of Table 8 were subjected to a separate 2 (prior individual or collaborative) $\times 2$ (younger or older adults) betweensubjects ANOVA. The ANOVA revealed a main effect of age $\left[F(1,74)=22.60, M S_{\mathrm{e}}=.02, \eta^{2}=.23\right]$, indicating that younger adults had greater corrected recall $(M=.43)$ than did older adults $(M=.26)$. There was no effect of prior collaboration or any interaction between prior collaboration and age $(F \mathrm{~s}<1)$.

Tables 7 and 8 also present the mean proportions of remember and know judgments for items recalled on Test 2 . Separate 2 (prior individual or collaborative) $\times 2$ (younger or older adults) ANOVAs were computed on remember and know judgments for total list recall and recall of the first 10 presented and critical items. Younger adults were more likely than older adults to assign both remember and know judgments to total list items (Table 7 ) and to the first 5 presented items (Table 8$)\left(F_{\mathrm{s}}>3.9, p \mathrm{~s}<.05, \eta^{2}>\right.$ $.05)$, reflecting the fact that younger adults recalled more items overall. In contrast, for the 5 critical items (Table 8), older adults showed more false remembering than did younger adults $\left[F(1,74)=6.41, M S_{\mathrm{e}}=.001, \eta^{2}=.08\right]$. Furthermore, remember judgments for the 5 critical items were also greater following prior collaboration, relative to prior individual recall $\left[F(1,74)=9.07, M S_{\mathrm{e}}=.001\right.$, $\left.\eta^{2}=.11\right]$, consistent with the idea that the subjects were incorporating others' responses into their own later recall and remembering them later. All age $\times$ prior collaboration interactions were not significant $\left(F_{\mathrm{S}}<1\right)$.

Recognition. The mean proportions of list recognition, critical recognition, and corrected recognition (hits minus false alarms) are presented in Table 9. The recognition test was always taken individually following two separate recall tests, so of course the results are influenced by prior testing. These analyses are only of the first 10 presented and critical items from the norms. To examine the effects of prior collaboration and age on list recognition, a 2 (prior individual or collaborative) $\times 2$ (younger or older adults) between-groups ANOVA was computed on the hit rates. The ANOVA revealed no main effects of age or prior collaboration and no interaction between age and collaboration $(F \mathrm{~s}<1)$. Both younger and older adults correctly recognized a similar proportion of list items, and this did not vary as a function of prior individual or collaborative recall.

False recognition rates revealed a somewhat different pattern. A separate 2 (prior individual or collaborative) $\times$ 2 (younger or older adults) ANOVA computed on the false alarm rates revealed no significant main effect of age and no significant main effect of prior collaboration

Table 8

Mean Proportions of Nonpooled Items Recalled From the First 10 Items From the Norms (Presented and Critical) and Mean Proportions of Remember and Know Responses on Subsequent Individual Free Recall Test (Experiment 2, $N=78$ )

\begin{tabular}{|c|c|c|c|c|c|c|}
\hline & \multicolumn{2}{|c|}{5 Presented } & \multicolumn{2}{|c|}{5 Critical } & \multicolumn{2}{|c|}{ Corrected } \\
\hline & Younger & Older & Younger & Older & Younger & Older \\
\hline Prior Individual & .49 & .33 & .07 & .05 & .42 & .28 \\
\hline Remember & .38 & .28 & .01 & .02 & .37 & .26 \\
\hline Know & .11 & .05 & .06 & .03 & .05 & .02 \\
\hline Prior Collaborative & .52 & .36 & .09 & .11 & .43 & .25 \\
\hline Remember & .41 & .27 & .02 & .06 & .39 & .21 \\
\hline Know & .11 & .09 & .07 & .05 & .04 & .04 \\
\hline
\end{tabular}


$\left(F_{\mathrm{S}}<1\right)$. However, both of these effects were qualified by a significant interaction between age and prior collaboration $\left[F(1,74)=4.28, M S_{\mathrm{e}}=.06, p=.042, \eta^{2}=\right.$ .06]. Follow-up comparisons conducted on the interaction suggest that younger adults' false recognition was not affected by prior collaboration $(t<1)$. However, older adults who had previously collaborated $(M=.65)$ had higher false alarm rates on the final recognition test than did older adults who had previously recalled alone $(M=$ .47) $[t(36)=2.22$, SEM $=.08]$.

Finally, corrected total recognition was obtained by subtracting false alarms from hits for the critical items. We do not provide data for all response options for corrected recognition because the nature of the correction does not make sense across response options (e.g., in the neither condition), and total recognition is of most interest (i.e., list added to list + self). A 2 (individual or collaborative) $\times 2$ (younger or older adults) ANOVA computed on corrected recognition revealed no main effects of age or prior collaboration $\left(F_{\mathrm{S}}<1\right)$. However, there was a significant interaction between age and prior collaboration $\left[F(1,74)=7.77, M S_{\mathrm{e}}=.04, \eta^{2}=.10\right]$. Post hoc comparison tests revealed that younger adults had higher corrected recognition following collaboration $(M=.40)$ than following prior individual recall $(M=.28)[t(38)=2.03$, $S E M=.06]$. In contrast, older adults showed marginally higher corrected recognition following individual recall $(M=.34)$ than following collaborative recall $(M=.22)$ $[t(36)=1.92, S E M=.06, p=.06]$. Apparently, younger adults are better able to selectively incorporate others' responses into their own memory reports. Older adults, on the other hand, may have incorporated most schemaconsistent items into their own memory reports; they could not differentiate which items had been suggested by their partners that were actually present in the lists and which were not.

\section{Discussion}

Considered together, the results of Experiment 2 confirmed that younger and older adults exhibited equivalent collaborative inhibition effects on an initial free recall test. On subsequent tests, collaborative inhibition disap- peared even though age differences in recall persisted. When appropriate corrections could be obtained in Experiment 2 with free recall, older adults showed the expected age-related decline, relative to younger adults. On the final recognition test, older adults had higher rates of false alarms than did younger adults, especially following collaboration.

\section{GENERAL DISCUSSION}

The present experiments provide the first comparison of unacquainted younger and older adults on tests of collaborative memory. The comparison resulted in novel findings regarding both list and critical recall and recognition.

\section{List Recall and Recognition}

Importantly, collaborative inhibition for categorized list items was obtained on initial tests of forced-report cued recall, free-report cued recall, and free recall for both younger and older adults and the magnitude of the effect did not vary with age. Consistent with past research, this finding suggests that collaborative inhibition is robust and occurs across several different testing situations (e.g., B. H. Basden et al., 1997; Weldon et al., 2000). Of greater interest is the novel finding that collaboration did not interact with age across retrieval conditions. Regardless of individual memory performance, the magnitude of the collaborative inhibition effect did not vary with age. Also, consistent with previous work with younger adults, collaborative inhibition for list items did not persist on subsequent individual recall or recognition tests for presented items for either younger or older adults (e.g., Finlay et al., 2000).

The findings for list recall can be generally interpreted within the framework of the retrieval strategy disruption hypothesis, although not without some difficulty. This idea maintains that in collaborative recall situations, another person's recall interferes with an individual's characteristic or preferred order of retrieval. A further prediction is that when a structure for retrieval is provided (e.g., by providing category name cues; cf. B. H. Basden et al., 1997),

Table 9

Mean Proportions of List and Critical Recognition on a Subsequent Individual Recognition Test (Experiment 2, $N=78$ )

\begin{tabular}{|c|c|c|c|c|c|c|}
\hline & \multicolumn{2}{|c|}{5 Presented } & \multicolumn{2}{|c|}{5 Critical } & \multicolumn{2}{|c|}{ Corrected } \\
\hline & Younger & Older & Younger & Older & Younger & Older \\
\hline \multicolumn{7}{|c|}{ Prior Individual } \\
\hline List & .45 & .58 & .48 & .40 & & \\
\hline List and self & .37 & .24 & .06 & .07 & & \\
\hline Total recognition & .82 & .82 & .54 & .47 & .28 & .34 \\
\hline Self & .02 & .04 & .01 & .07 & & \\
\hline Neither & .16 & .14 & .45 & .46 & & \\
\hline \multicolumn{7}{|c|}{ Prior Collaborative } \\
\hline List & .36 & .44 & .37 & .44 & & \\
\hline List and self or other & .52 & .43 & .11 & .21 & & \\
\hline Total recognition & .88 & .87 & .48 & .65 & .40 & .22 \\
\hline Self or other & .00 & .01 & .00 & .01 & & \\
\hline Neither & .12 & .12 & .52 & .34 & & \\
\hline
\end{tabular}


retrieval disruption and collaborative inhibition should be minimized. However, in the present experiments, we found no interaction between collaboration and retrieval condition, which is a problem for the hypothesis. Our outcome may differ from others because our categorized lists contained the highest taxonomic frequency exemplars from each category (in contrast, the lists used by B. H. Basden et al. [1997] contained low-taxonomic-frequency exemplars). High-taxonomic-frequency exemplars potentially allowed the subjects in all the experimental conditions to organize lists by category, so they were less affected by retrieval condition (i.e., even in free recall, items were recalled according to category). However, this speculation awaits further tests.

\section{Critical Recall and Recognition}

Regarding false recall and false recognition, the experiments reported here also replicated previous findings showing that older adults demonstrated higher rates of false recall than did younger adults (e.g., Balota et al., 1999) and that forced recall led to greater false recollection on subsequent individual tests (e.g., Ackil \& Zaragoza, 1998; Roediger, Jacoby, \& McDermott, 1996; Roediger et al., 1993; Zaragoza, Payment, Ackil, \& Beck, 2001). Again, the novel contribution was our examination of the role of collaboration in such effects. Interestingly, collaborative inhibition was obtained only for critical items on the forced-report cued recall test. No collaborative inhibition was obtained for critical items under free-report cued recall instructions in Experiment 1 or free recall instructions in Experiment 2, as measured in number of intrusions produced. These results suggest that collaboration may have differing effects on false recollections depending on retrieval conditions (although Experiment 2's free recall results may be clouded by floor effects). Furthermore, the type of retrieval condition affected the subsequent impact of collaboration, because subsequent tests reflected prior collaboration only after a free recall test. Specifically, older adults showed greater false recognition than did younger adults in this condition. Prior collaboration may have exaggerated older adults' tendency toward higher false alarms on a subsequent individual recognition test after free recall, because free recall allows subjects to establish their own response criteria (unlike forced-report cued recall) and is not structured by retrieval cues (unlike free-report cued recall).

The finding that older adults demonstrated increased false recognition following collaborative free recall is inconsistent with previous evidence suggesting that older adults are able to correct errors on collaborative memory tasks (Ross et al., 2008; Ross et al., 2004). Three important differences exist between the present study and those reported by Ross and colleagues. First, our study used pairs of strangers, whereas previous studies showing error correction used older adult couples who had been married for many years. Potentially, subjects may feel more comfortable correcting errors of someone well known, relative to a stranger. The second critical difference is that the turntaking procedure employed in the present study contrasts with the unstructured recall procedure employed by Ross and colleagues. The turn-taking procedure may encourage older adults to guess, rather than pass on their turn, due to increased pressure to produce an item during one's turn (cf. B. H. Basden et al., 1998; Perlmutter, 1953; Thorley \& Dewhurst, 2007), and does not encourage consensus or correction. Finally, in the present study, older adults' increased erroneous recall and recognition following collaborative free recall occurred on a subsequent individual recognition test, not during collaboration.

One explanation of older adults' higher false recall and false alarms following prior collaborative free recall may be that once the items were suggested (and not corrected), they were subject to source-monitoring problems that are known to be greater in older adults (e.g., Johnson et al., 1993). According to the source-monitoring framework, accurate recollection requires retention of both the to-beretrieved information itself and the source of that information. Subjects attribute a source to information by assessing the qualitative characteristics associated with the item (e.g., items presented on a computer screen might have perceptual characteristics that internally generated items did not have). Given the turn-taking procedure of the present experiments, the subjects were exposed to both accurate and inaccurate items during collaborative recall. Because the majority of items generated were categorically consistent with those studied, the subjects had the difficult task of deciding whether an item they remembered from the experiment had occurred in the study list and/or had been suggested during initial recall. Older adults have difficulties making source attributions (e.g., McIntyre \& Craik, 1987), and so they probably were disadvantaged in correctly identifying which items had been presented in the study lists. Although both false and veridical items were suggested during collaborative recall under each retrieval manipulation, older adults showed increased false recognition only following free recall. Older adults might have had an especially difficult time monitoring the source of items produced on a prior free recall test, because this test permitted the subjects to set their response threshold and organization for all items (as opposed to forced-report cued recall, in which the subjects knew that some items produced were guesses). In other words, monitoring may be more difficult for older adults following free recall because items produced during free recall are primarily attributed to having been accurately retrieved, whereas items produced during cued recall may be attributed to guessing or construction, rather than to accurate memory retrieval. This tendency would be greatest during forced-report cued recall.

In summary, the primary goal of the present experiments was to begin to examine possible age differences in collaborative memory effects among unacquainted dyads, and we obtained several interesting findings. First, younger and older adults demonstrated equivalent collaborative inhibition effects on several types of initial tests: forced-report cued recall, free-report cued recall, and free recall. This conclusion derives from null effects and, so, must be interpreted with caution, but the consistent failure under three different sets of retrieval conditions bolsters our conclusion. In addition, our designs were powerful 
enough to obtain other effects. Consistent with prior research, older adults showed higher levels of false recall, false recognition, and false remembering than did younger adults. The higher level of false remembering is especially noteworthy (see also Meade \& Roediger, 2006). Older adults were also more likely to make errors on a final recognition test following previous collaboration under free recall instructions, probably due to impaired source monitoring (Roediger \& McDaniel, 2007).

\section{AUTHOR NOTE}

This research was partially supported by National Institute of Aging Grant AG17481. We thank Jane McConnell for help recruiting subjects in Experiment 1, Judy Morrill and Regina Demis at the Bozeman Senior Center for providing testing rooms and help recruiting subjects in Experiment 2, and Keith Hutchison, Celia Harris, Pooja Agarwal, Andrew Butler, and Franklin Zaromb for helpful comments. Correspondence concerning this article should be addressed to M. L. Meade, Department of Psychology, Montana State University, P.O. Box 173440, Bozeman, MT 59717 (e-mail: mlmeade@montana.edu).

\section{REFERENCES}

ACKIL, J. K., \& Zaragoza, M. S. (1998). Memorial consequences of forced confabulation: Age differences in susceptibility of false memories. Developmental Psychology, 34, 1358-1372.

ANDERSSON, J., \& RöNNBERG, J. (1995). Recall suffers from collaboration: Joint recall effects of friendship and task complexity. Applied Cognitive Psychology, 9, 199-211.

ANDERsson, J., \& RönNBERG, J. (1996). Collaboration and memory: Effects of dyadic retrieval on different memory tasks. Applied Cognitive Psychology, 10, 171-181.

Balota, D. A., Cortese, M. J., DucheK, J. M., Adams, D., RoediGer, H. L., III, McDermott, K. B., \& Yerys, B. E. (1999). Veridical and false memories in healthy older adults and in dementia of the Alzheimer's type. Cognitive Neuropsychology, 16, 361-384.

Balota, D. A., Dolan, P. O., \& DucheK, J. M. (2000). Memory changes in healthy older adults. In E. Tulving \& F. I. M. Craik (Eds.), The Oxford handbook of memory (pp. 395-409). New York: Oxford University Press.

BASden, B. H., BASden, D. R., Bryner, S., \& Thomas, R. L., III (1997) A comparison of group and individual remembering: Does collaboration disrupt retrieval strategies? Journal of Experimental Psychology: Learning, Memory, \& Cognition, 23, 1176-1189.

Basden, B. H., Basden, D. R., \& Henry, S. (2000). Costs and benefits of collaborative remembering. Applied Cognitive Psychology, 14, 497-507.

Basden, B. H., Basden, D. R., Thomas, R. L., III, \& Souphasith, S. (1998). Memory distortion in group recall. Current Psychology: Developmental, Learning, Personality, Social, 16, 225-246.

BASDEN, D. R., \& BASDEN, B. H. (1995). Part-list cuing inhibition as retrieval strategy disruption. Journal of Experimental Psychology: Learning, Memory, \& Cognition, 21, 1659-1672.

Battig, W. F., \& Montague, W. E. (1969). Category norms for verbal items in 56 categories: A replication and extension of the Connecticut category norms. Journal of Experimental Psychology Monographs, 80(3, Pt. 2), 1-45.

Blumen, H. M., \& Rajaram, S. (2008). Influence of re-exposure and retrieval disruption during group collaboration on later individual recall. Memory, 16, 231-244.

BouchaRd, T. J., \& HARE, M. (1970). Size, performance, and potential in brainstorming groups. Journal of Applied Psychology, 54, 51-55.

CoHEN, J. (1988). Statistical power analysis for the behavioral sciences (2nd ed.). Hillsdale, NJ: Erlbaum.

CRAIK, F. I. M. (1983). On the transfer of information from primary to secondary memory. Philosophical Transactions of the Royal Society $B, \mathbf{3 0 2}, 341-359$.

CraIK, F. I. M., \& McDowd, J. M. (1987). Age differences in recall and recognition. Journal of Experimental Psychology: Learning, Memory, \& Cognition, 13, 474-479.
DEESE, J. (1959). On the prediction of occurrence of particular verbal intrusions in immediate recall. Journal of Experimental Psychology, 58, $17-22$.

Dixon, R. A. (1996). Collaborative memory and aging. In D. Herrmann, C. McEvoy, C. Hertzog, P. Hertel, \& M. K. Johnson (Eds.), Basic and applied memory research: Theory in context (Vol. 1, pp. 359-383). Mahwah, NJ: Erlbaum.

Dixon, R. A. (1999). Exploring cognition in interactive situations: The aging of $n+1$ minds. In T. M. Hess \& F. Blanchard-Fields (Eds.), Social cognition and aging (pp. 267-290). San Diego: Academic Press.

Dixon, R. A., Gagnon, L. M., \& Crow, C. B. (1998). Collaborative memory accuracy and distortion: Performance and beliefs. In M. J. Inton-Peterson \& D. L. Best (Eds.), Memory distortions and their prevention (pp. 63-88). Mahwah, NJ: Erlbaum.

Erdelyi, M. H., FinKs, J., \& Feigin-Pfau, M. B. (1989). The effect of response bias on recall performance, with some observations on processing bias. Journal of Experimental Psychology: General, 118, 245-254.

Finlay, F., Hitch, G. J., \& Meudell, P. R. (2000). Mutual inhibition in collaborative recall: Evidence for a retrieval based account. Journal of Experimental Psychology: Learning, Memory, \& Cognition, 26, 1556-1567.

Folstein, M. F., Folstein, S. E., \& McHugh, P. R. (1975). Mini-mental state: A practical method for grading the cognitive state of patients for the clinician. Journal of Psychiatric Research, 12, 185-198.

Gallo, D. A. (2006). Associative illusions of memory: False memory research in DRM and related tasks. New York: Psychology Press.

GARDINER, J. M. (1988). Functional aspects of recollective experience. Memory \& Cognition, 16, 309-313.

Gould, O. N., Osborn, C., Krein, H., \& Mortenson, M. (2002). Collaborative recall in married and unacquainted dyads. International Journal of Behavior Development, 26, 36-44.

Gould, O. N., Trevithick, L., \& Dixon, R. A. (1991). Adult age differences in elaborations produced during prose recall. Psychology \& Aging, 6, 93-99.

Harris, C. B., Paterson, H. M., \& Kemp, R. I. (2008). Collaborative recall and collective memory: What happens when we remember together? Memory, 16, 213-230.

Hashtroudi, S., Johnson, M. K., \& Chrosniak, L. D. (1989). Aging and source monitoring. Psychology \& Aging, 4, 106-112.

Henkel, L. A. (2007). The benefits and costs of repeated memory tests for young and older adults. Psychology \& Aging, 22, 580-595.

JACOBY, L. L., JenNingS, J. M., \& HAY, J. F. (1996). Dissociating automatic and consciously controlled processes: Implications for diagnosis and rehabilitation of memory deficits. In D. Herrmann, C. McEvoy, C. Hertzog, P. Hertel, \& M. K. Johnson (Eds.), Basic and applied memory research: Theory in context (Vol. 1, pp. 161-193). Mahwah, NJ: Erlbaum.

JenNingS, J. M., \& JACOBY, L. L. (1997). An opposition procedure for detecting age-related deficits in recollection: Telling effects of repetition. Psychology \& Aging, 12, 352-361.

JohANSSON, [N.] O., ANDERSSON, J., \& RönnBerg, J. (2000). Do elderly couples have a better prospective memory than other elderly couples when they collaborate? Applied Cognitive Psychology, 14, 121-133.

Johansson, N. O., Andersson, J., \& Rönnberg, J. (2005). Compensating strategies in collaborative remembering in very old couples. Scandinavian Journal of Psychology, 46, 349-359.

Johnson, M. K., Hashtroudi, S., \& Lindsay, D. S. (1993). Source monitoring. Psychological Bulletin, 114, 3-28.

Kane, M. J., \& Hasher, L. (1995). Interference. In G. L. Maddox (Ed.), Encyclopedia of aging (2nd ed., pp. 514-516). New York: Springer.

KorIaT, A., \& GoldSMITH, M. (1996). Monitoring and control processes in the strategic regulation of memory accuracy. Psychological Review, 103, 490-517.

McInTYRe, J. S., \& Craik, F. I. M. (1987). Age differences in memory for item and source information. Canadian Journal of Psychology, 41, 175-192.

Meade, M. L., \& Roediger, H. L., III (2002). Explorations in the social contagion of memory. Memory \& Cognition, 30, 995-1009.

Meade, M. L., \& Roediger, H. L., III (2006). The effect of forced recall on illusory recollection in younger and older adults. American Journal of Psychology, 119, 433-462.

Meade, M. L., Roediger, H. L., III, \& Geraci, L. D. (2009). Predicting 
false memories in older adults from neuropsychological tests. Manuscript in preparation.

Multhaup, K. S. (1995). Aging, source, and decision criteria: When false fame errors do and do not occur. Psychology \& Aging, 10, 492-497.

Perlmutter, H. V. (1953). Group memory of meaningful material. Journal of Psychology: Interdisciplinary \& Applied, 35, 361-370.

RAJARAM, S. (1993). Remembering and knowing: Two means of access to the personal past. Memory \& Cognition, 21, 89-102.

Rajaram, S., \& Pereira-Pasarin, L. P. (2007). Collaboration can improve individual recognition memory: Evidence from immediate and delayed tests. Psychonomic Bulletin \& Review, 14, 95-100.

RitTer, W., \& BuschKe, H. (1974). Free, forced, and restricted recall in verbal learning. Journal of Experimental Psychology, 6, 1204-1207.

RoEDIGER, H. L., III (1973). Inhibition in recall from cueing with recall targets. Journal of Verbal Learning \& Verbal Behavior, 12, 644-657.

Roediger, H. L., III, Jacoby, J. D., \& McDermott, K. B. (1996). Misinformation effects in recall: Creating false memories through repeated retrieval. Journal of Memory \& Language, 35, 300-318.

Roediger, H. L., III, \& McDaniel, M. A. (2007). Illusory recollections in older adults: Testing Mark Twain's conjecture. In M. Garry \& H. Hayne (Eds.), Do justice and let the sky fall: Elizabeth F. Loftus and her contributions to science, law, and academic freedom (pp. 105136). Mahwah, NJ: Erlbaum.

Roediger, H. L., III, \& MCDermott, K. B. (1995). Creating false memories: Remembering words not presented in lists. Journal of Experimental Psychology: Learning, Memory, \& Cognition, 21, 803-814.

Roediger, H. L., III, Meade, M. L., \& Bergman, E. T. (2001). Social contagion of memory. Psychonomic Bulletin \& Review, 8, 365-371.

Roediger, H. L., III, \& PAYNe, D. G. (1985). Recall criterion does not affect recall level or hypermnesia: A puzzle for generate/recognize theories. Memory \& Cognition, 13, 1-7.

Roediger, H. L., III, SRINIVAS, K., \& Waddill, P. (1989). How much does guessing influence recall? Comment on Erdelyi, Finks, and Feigin-Pfau. Journal of Experimental Psychology: General, 118, 255-257.

Roediger, H. L., III, Wheeler, M. A., \& Rajaram, S. (1993). Remembering, knowing, and reconstructing the past. In D. L. Medin (Ed.), The psychology of learning and motivation: Advances in research and theory (Vol. 30, pp. 97-134). New York: Academic Press.
Ross, M., Spencer, S. J., Blatz, C. W., \& Restorick, E. (2008). Collaboration reduces the frequency of false memories in older and younger adults. Psychology \& Aging, 23, 85-92.

Ross, M., Spencer, S. J., Linardatos, L., Lam, K. C. H., \& PeruNOVIC, M. (2004). Going shopping and identifying landmarks: Does collaboration improve older people's memory? Applied Cognitive Psychology, 18, 683-696.

SHIPLEY, W. C. (1946). Institute of Living Scale. Los Angeles: Western Psychological Services.

Smith, S. M., Ward, T. B., Tindell, D. R., Sifonis, C. M., \& WilkenFELD, M. J. (2000). Category structure and created memories. Memory \& Cognition, 28, 386-395.

Steiner, I. D. (1972). Group processes and productivity. New York: Academic Press.

Thorley, C., \& Dewhurst, S. A. (2007). Collaborative false recall in the DRM procedure: Effects of group size and group pressure. European Journal of Cognitive Psychology, 19, 867-881.

Tulving, E. (1985). Memory and consciousness. Canadian Psychologist, 26, 1-12.

Weldon, M. S. (2001). Remembering as a social process. In D. L. Medin (Ed.), The psychology of learning and motivation: Advances in research and theory (Vol. 40, pp. 67-120). San Diego: Academic Press.

Weldon, M. S., \& Bellinger, K. D. (1997). Collective memory: Collaborative and individual processes in remembering. Journal of Experimental Psychology: Learning, Memory, \& Cognition, 23, 11601175.

Weldon, M. S., Blair, C., \& Huebsch, D. (2000). Group remembering: Does social loafing underlie collaborative inhibition? Journal of Experimental Psychology: Learning, Memory, \& Cognition, 26, 1568-1577.

Wright, D. B., \& KLumpP, A. (2004). Collaborative inhibition is due to the product, not the process, of recalling in groups. Psychonomic Bulletin \& Review, 11, 1080-1083.

Zaragoza, M. S., Payment, K. E., Ackil, J. K., \& Beck, M. (2001). Interviewing eyewitnesses: Forced confabulation and confirmatory feedback increase false memories. Psychological Science, 12, 473-477.

(Manuscript received December 10, 2008; revision accepted for publication May 10, 2009.) 